Review article

Central Eur J Paed 2018; 14(1): 27-36

DOI $10.5457 / \mathrm{p} 2005-114.196$

\title{
The impact of vitamin D: From a fetus to an infant
}

\author{
Aneta Soltirovska Salamon, Darja Paro - Panjan \\ University Medical Centre Ljubljana \\ Division of Pediatrics, Department \\ of Neonatology, Ljubljana, Slovenia \\ Correspondence: \\ aneta.soltirovska@kclj.si \\ Tel.: + 38615229274 \\ Fax.: + 38615224035 \\ Received: December 6, 2017 \\ Accepted: February 1, 2018 \\ Key words: Vitamin D - Deficiency • \\ Outcome • Pregnancy • Infant.

\begin{abstract}
The focus of this paper is to review the data on the classic and nonclassic role of VD with regards to pregnancy and the newborn period. Over the past decade, new evidence has shown that vitamin D (VD) deficiency, in addition to its classical role in calcium metabolism and bone homeostasis, may contribute to the risk of developing a wide range of chronic diseases. VD may produce a wide array of favourable biological effects via genomic, non-genomic or intracrine mechanisms, and therefore contributes to the improvement of human health. Some of these effects may be even more important during pregnancy. Data from animal and human studies implicate maternal VD deficiency as a significant risk factor for several adverse outcomes affecting maternal, foetal and child health. In the newborn period, these comprise bone health, growth and immune response. Conclusion - Recent evidence supports the fact that low maternal vitamin D status is associated with an increased risk of adverse pregnancy outcomes. This paper investigates the effects of vitamin D on the placento-foetal unit and the mother, in terms of calcium metabolism and non-calcium effects.
\end{abstract}

\section{Introduction}

From conception onward, a child develops under the influence of a series of biological events that enable the maturation of tissues, growth and adaptation. This multi-factorial process represents the interplay of genetic, environmental and dietary aspects. The biological background of various influences on the developmental process has been the subject of research in numerous studies on animals over the past few years. It has been proven that, within a critical period during intrauterine development, the so-called "window of vulnerability", foetal development is sensitive to the changing environment, which enables phenotypic diversity (1). During this time, certain parameters as- sociated with the mother, such as vitamin D (VD) deficiency, may affect the body composition, bone mass, and the physiology of the child (2). In the past decade, different studies have enabled researchers to establish a link between VD status in pregnant women and the outcome of pregnancy, the health of the foetus and the newborn infant, as well as the health of the offspring in their childhood and adulthood (2). The classic action of VD in maintaining calcium homeostasis and its impact on bone health has been known for a long time (3). However, recent findings suggest that VD also plays a role in the process of immunomodulation, cell proliferation and differentiation, as well as in many other physiological functions in various tissues and organs, including the brain, pancreas, 
kidneys, placenta and heart (3). Lack of VD during pregnancy is very common in many parts of the world, and there is a link between low VD levels and the possibility of adverse outcomes $(4,5)$. Despite reports on the wide prevalence of VD deficiency and its potential consequences, the criteria for determining the optimal level in the body, and thus the quantity of VD intake needed to maintain these adequate levels, remain a matter of debate $(6,7,8)$.

This paper presents data from the scientific literature, and discusses the role of VD during pregnancy, as well as the effects of maternal VD deficiency on the offsprings' health, regarding their bones and their entire organism (non-skeletal health).

\section{Physiology and the biological role of vitamin D}

VD, or calciferol, is regarded as a pro-hormone. The term VD defines a group of fat-soluble secosteroids, of which the main representatives are $\mathrm{VD}_{2}$ (ergocalciferol) and $\mathrm{VD}_{3}$ (cholecalciferol). Exposure to sunlight, to ultraviolet radiation $B(\mathrm{UVB})$ in particular, triggers the conversion of pro- $\mathrm{VD}_{3}$ in the skin (7-dehydrocholesterol) into $\mathrm{VD}_{3}$, which binds to the binding protein for VD; it is then transported into the bloodstream and accumulated in adipose tissue or metabolised in the liver. Skin synthesis is the main source of VD, although certain foods, such as fish oil and cod liver oil, also provide direct intake of $\mathrm{VD}_{3}(3,9)$. Additionally, $\mathrm{VD}_{2}$ is produced by UVB irradiation of the ergosterol in plants and fungi, but has lower bioavailability than $\mathrm{VD}_{3}$. All forms of VD are biologically inactive until hydroxylated, which first takes place in the liver with the enzyme 25a-hydroxylase. This results in 25-hydroxy-vitamin D [25(OH)D]. Since this conversion is not controlled, the concentration of $25(\mathrm{OH}) \mathrm{D}$ increases in proportion to the synthesis and VD intake. The second hydroxylation occurs in the kidneys, with the assistance of $1 \alpha$-hydroxylase, resulting in 1,25-dihydroxy-vitamin $\mathrm{D}\left[1,25(\mathrm{OH})_{2} \mathrm{D}\right]$, which is a biologically active hormone. Renal synthesis of $1,25(\mathrm{OH})_{2} \mathrm{D}$ is stimulated by the parathyroid hormone (PTH), and inhibited by the fibroblast growth factor. Serum calcium and phosphorus levels also stimulate the formation of active $\operatorname{VD}(3,4)$ (Fig. 1).

The classic effect of VD is the homoeostasis of calcium and phosphorus, promotion of osteoid mineralization and thereby the maintenance of bone health (3). However, many tissues in the body (including the placenta, prostate, breast, colon, lung, bone, parathyroids, pancreas, vascular walls and the immune system) have receptors to bind the active form of VD, and many of them contain an enzyme to convert $25(\mathrm{OH}) \mathrm{D}$ to $1,25(\mathrm{OH})_{2} \mathrm{D}$. Locally produced $1,25(\mathrm{OH})_{2} \mathrm{D}$ serves as an autocrine/paracrine factor that is essential for cell proliferation, differentiation, apoptosis, inhibition of angiogenesis and immunomodulation even early in development $(3,4,10)$. For these reasons, it has been suggested that VD also has an extra-skeletal role - a non-classic action; for example, it act to affect the innate and acquired immune response, reduce cancer cell proliferation, influence the cardiovascular function and blood pressure, as well as hormone secretion, including the promotion of insulin secretion $(3,4,10)$.

\section{Classification of vitamin D status}

The standard method for assessing the VD status in the body is to determine the $25(\mathrm{OH}) \mathrm{D}$ serum levels. $25(\mathrm{OH}) \mathrm{D}$ is a stable metabolite of serum VD, with a half-life of about 3 weeks, and it is the most appropriate indicator of VD status (10). Recently the criterion for the optimal VD status has been defined as the concentration of $25(\mathrm{OH}) \mathrm{D}$ 


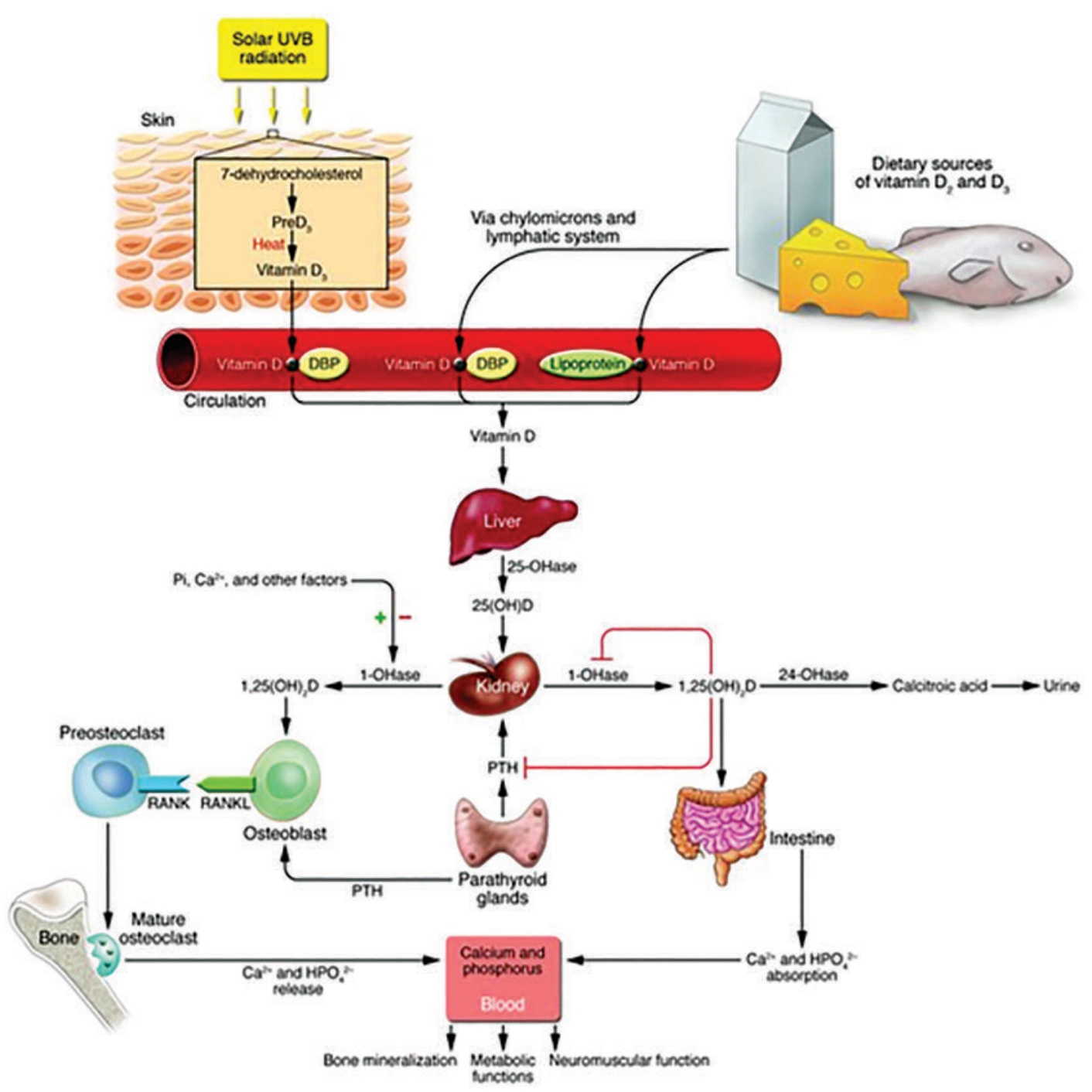

Fig. 1. Vitamin D metabolism.

Vitamin $\mathrm{D}$ is either produced in the skin by exposure to UVB radiation or is ingested in the diet. Vitamin $\mathrm{D}$ (D represents vitamin $\mathrm{D}_{2}$ or vitamin $\mathrm{D}_{3}$ ) is converted by the vitamin $\mathrm{D}-25$-hydroxylase (25-OHase) in the liver to $25(\mathrm{OH}) \mathrm{D}$. $25(\mathrm{OH}) \mathrm{D}$ is converted in the kidneys by $1-\mathrm{OH}$ ase to $1,25(\mathrm{OH})_{2} \mathrm{D}$. Once formed, $1,25(\mathrm{OH})_{2} \mathrm{D}$ enhances intestinal calcium and phosphorus absorption, and stimulates the expression of RANKL on the osteoblasts to interact with its receptor RANK on preosteoclasts to induce mature osteoclastic activity, which releases calcium and phosphorus $\left(\mathrm{HPO}_{4}^{2-}\right)$. In addition, 1,25( $\left.\mathrm{OH}\right)_{2} \mathrm{D}$ inhibits the renal 1-OHase and stimulates the expression of the renal 25(OH)D-24-hydroxylase (24-OHase). The induction of the 24-OHase results in the destruction of $1,25(\mathrm{OH})_{2} \mathrm{D}$ into a water-soluble inactive metabolite calcitroic acid, $\mathrm{PreD}_{3}$, previtamin D. (By Holic MF. J Clin Invest 2006). Adapted with permission from Holic MF.

necessary to achieve not only adequate bone health, but also the health of the entire organism (11). Recent recommendations by the Endocrinological Association stressed that the optimal concentration of $25(\mathrm{OH})$ $\mathrm{D}$ is above $75 \mathrm{nmol} / \mathrm{L}$, when the serum levels of VD and PTH are in equilibrium (12). Thus, a $25(\mathrm{OH}) \mathrm{D}$ concentration lower than 
$50 \mathrm{nmol} / \mathrm{l}(<20 \mathrm{ng} / \mathrm{ml}$ or $<50 \mathrm{nmol} / \mathrm{l})$ is recognized as VD deficiency, suboptimal status $(20-30 \mathrm{ng} / \mathrm{ml}(50-75 \mathrm{nmol} / \mathrm{l}))$ and the target concentration for optimal VD effects [30-50 $\mathrm{ng} / \mathrm{ml}(75-125 \mathrm{nmol} / \mathrm{l})]$ (13). This level coincides with the outcome of pregnancy and the health of the foetus, indicating that this classification may also be appropriate during pregnancy and lactation (14). However data from the Hollis study suggest that a circulating $25(\mathrm{OH}) \mathrm{D}$ level of approximately 100 $\mathrm{nmol} / \mathrm{l}(40 \mathrm{ng} / \mathrm{ml})$ is required to optimize production of $1,25(\mathrm{OH})_{2} \mathrm{D}$ during human pregnancy (15).

\section{Prevalence of VD deficiency during pregnancy}

VD deficiency is being increasingly recognized as a global epidemic that affects children, adolescents, adults and the elderly. The prevalence of VD deficiency is rising, mainly due to the modern lifestyle and malabsorption disorders $(14,16)$. The scientific literature offers no evidence supporting the benefits of population screening for determining VD status. According to the current recommendations, the level of 25-hydroxy VD is tested in individuals with diseases such as rickets, osteomalacia, osteopenia or osteo- porosis, chronic kidney disease, liver failure, malabsorption, and obesity, in patients treated with anticonvulsant and/or antiretroviral drugs and glucocorticoids, and in pregnant and lactating women $(14,16)$. The prevalence of $\mathrm{VD}$ deficiency in pregnancy varies between 20 and $84 \%$ (17). A number of recent studies, which have estimated dietary intake of VD during pregnancy in different geographical locations, have reported significant differences in VD status, depending on the latitude, season, sun exposure and VD intake. In a Slovenian study, VD deficiency and insufficiency were found in 14 and $41 \%$ of pregnant women, respectively, and optimal levels were found in less than half of the study population (18).

\section{Consequences of VD deficiency during pregnancy}

There are a number of plausible biological pathways through which VD could influence maternal and foetal health during pregnancy. VD has important immune-modulating properties, helping to establish a proper maternal immune response to the placenta, reducing obstetrics risks associated with VD deficiency $(17,19)$ (Fig. 2).

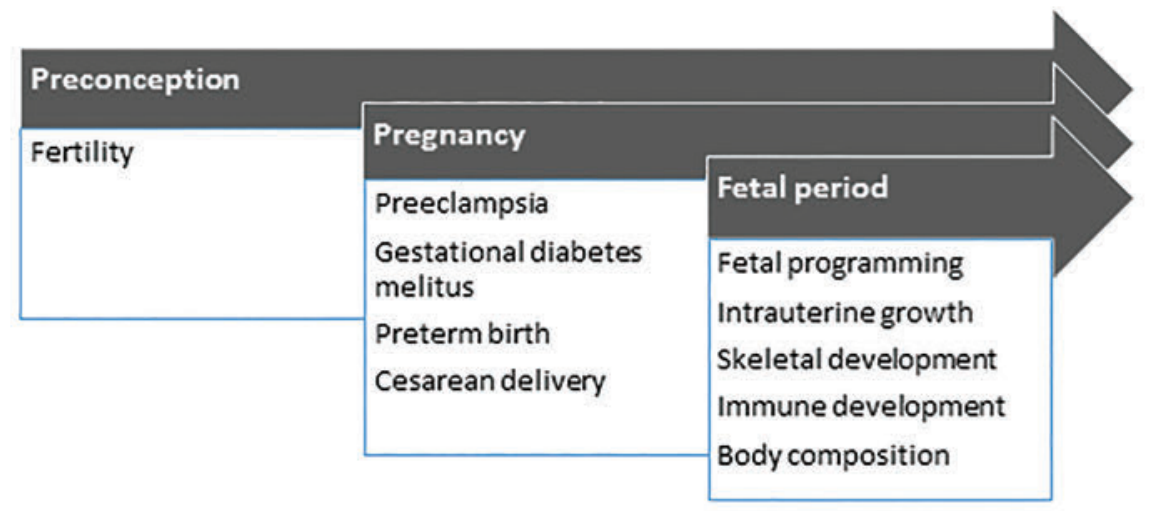

Fig. 2. The health implications of vitamin D deficiency at different stages. 


\section{Preeclampsia/gestational hypertension}

One of the complications most closely associated with VD deficiency during pregnancy is preeclampsia (PE). Compared with normal pregnancies, $\mathrm{PE}$ is characterized by marked changes in $\mathrm{VD}$ and calcium metabolism, and already in the early 1990's, the role of VD in the pathogenesis of PE was hypothesized (18). Many observational studies have found an increased risk of preeclampsia in women with low VD status (20-23). Women with PE are known to have lower circulating $25(\mathrm{OH}) \mathrm{D}_{3}$ levels than normotensive pregnant women (20-23).

In nested case-control studies, VD deficiency in pregnancy $<50 \mathrm{nmol} / \mathrm{l}$ of $25(\mathrm{OH})$ $\mathrm{D}_{3}$ was associated with almost fourfold odds of severe PE (20), and VD deficiency $<37.5$ $\mathrm{nmol} / \mathrm{l}$ was even associated with a fivefold risk of developing PE (20). Bodnar et al. (21) showed that $25(\mathrm{OH}) \mathrm{D}_{3}$ deficiency before 22 weeks of gestation is an independent risk factor for the manifestation of PE. Additionally, many randomized controlled trials, which have been undertaken to determine the impact of VD supplementation in PE patients, concluded that VD supplementation reduces the risk of PE (23). The mechanism suggested is the regulation of maternal and placental immunological and inflammatory responses, as has been shown in experimental models (24). In syncytiotrophoblasts from preeclamptic pregnancies, the expression and activity of $1 \alpha$-hydroxylase are restricted, suggesting an important role for VD at the placental site of the disease, and endorsing the role of VD in the regulation of the target genes associated with implantation, trophoblast invasion, and implantation tolerance $(24,25)$.

\section{Gestational diabetes mellitus}

VD plays a role in glucose homeostasis by multiple mechanisms: it regulates calcium levels, which in turn regulate insulin production and secretion by the endocrine pancreas $(26,27)$. It also improves the sensitivity to insulin of the target cells, such as adipose tissue, liver and skeletal muscles (26). Through its role in the regulation of immune cells, it protects $\beta$ cells from detrimental immune attacks and even enhances their function (27). The role of VD in the development of pregnancy-related diabetes has been the subject of numerous studies, and it has been shown that VD deficiency affects the altered glucose homeostasis during pregnancy (28). Eight observational studies have recently been conducted to study the association of VD with gestational diabetes mellitus (GDM), and reported an inverse relationship between VD status in early pregnancy and risk of gestational diabetes (23). In a cohort of pregnant women whose VD values were measured before the gestational age of 16 weeks, an increase in the level of VD was associated with a reduced risk for the development of hyperglycaemia at the gestational age of 24-28 weeks (29). In contrast, some studies failed to establish a role of VD in the prevention of GDM (23). Although VD deficiency, or the dysfunction of VD receptors, relates to the pathogenesis of type 1 and type 2 diabetes, its role in GDM remains inconclusive.

\section{Preterm delivery}

One of the most common causes of preterm delivery is infection. Thus, through its role in anti-inflammatory pathways via nuclear factor- $\kappa \mathrm{B}$ inhibition, VD could play a role in decreasing the incidence of infections and thereby preterm births (30). However, the exact role of VD in the pathogenesis of preterm birth has not yet been clearly defined. Many observational and interventional studies have investigated the association, with a lack of consistency in their results. Bodnar et al. (31) conducted a case control study with 1,126 cases and 2,327 controls, and found a protective association of VD sufficiency and preterm birth, after adjusting for the confounding factors. McDonnell et al. (32) 
found a clear association between maternal $25(\mathrm{OH}) \mathrm{D}$ concentration and preterm birth risk in the general obstetrical population. Thus women with a $25(\mathrm{OH}) \mathrm{D}$ concentration of $\geq 40 \mathrm{ng} / \mathrm{ml}$ had a $62 \%$ lower risk of preterm birth compared to those with concentrations $<20 \mathrm{ng} / \mathrm{ml}$. These findings support the inverse association between maternal $25(\mathrm{OH}) \mathrm{D}$ and PTB risk found in the Hollis and Wagner et al. (33) randomized clinical trials, as well as epidemiological studies. However, other studies did not support these findings. A meta-analysis carried out by Pérez López et al. (34) showed conflicting reports on the role of vitamin $\mathrm{D}$ and the risk of preterm birth.

\section{Other impacts of VD status during pregnancy}

VD deficiency during pregnancy has been also significantly associated with an increased incidence of bacterial vaginosis (35). The incidence of bacterial vaginosis during pregnancy is important because it is associated with adverse outcomes, such as premature rupture of the membranes, premature delivery and the incidence of postpartum endometritis. In addition, a higher level of parturition by Caesarean section has also been reported in pregnant women with VD deficiency, although some other studies indicate that the method of delivery is independent of maternal VD status (36).

\section{The influence of maternal VD status on offspring health}

Numerous studies have shown that there is a positive correlation between the cord blood levels of $25(\mathrm{OH}) \mathrm{D}$ in the newborn and the maternal VD status, and that it represents approximately 60 to $89 \%$ of the maternal value (1). Therefore, maintaining optimal VD intake during pregnancy is essential to prevent insufficiency in foetal, neonatal and early childhood development. Physiologically active metabolite $1,25(\mathrm{OH})_{2} \mathrm{D}$ does not cross the placenta $(1,37)$. Foetal kidneys and placenta provide the foetal circulation with $1,25(\mathrm{OH})_{2} \mathrm{D}$ by expressing CYP27B1. Hormones involved in foetal growth also influence CYP27B1 activity, including insulin like growth factor 1, human placental lactogen, PTH-related protein (PTHrP), estradiol, and prolactin (38).

\section{Bone health in newborns}

Lack of VD during pregnancy may have an impact on foetal and neonatal bone mass and bone mineralization. In their study, Weiler et al. (39) detected a lower bone mineral content per kilogram of body weight in newborns with lower levels of $25(\mathrm{OH}) \mathrm{D}$ in the cord blood. Viljakainen (40) studied the relationship between the levels of $25(\mathrm{OH})$ $\mathrm{D}$ in the first trimester of pregnancy and the neonatal bone mass, measured by peripheral quantitative computed tomography in the postpartum period. He found that the newborns of mothers whose average concentration of $25(\mathrm{OH}) \mathrm{D}$ was below $43 \mathrm{nmol} / \mathrm{l} \mathrm{ex}-$ hibited lower tibia bone mass than the newborns of mothers whose average concentration of $25(\mathrm{OH}) \mathrm{D}$ was higher than $43 \mathrm{nmol} / \mathrm{l}$.

Studies have shown that chronic VD deficiency in the mother has a negative effect on the development of the skeleton of the foetus. Using three-dimensional ultrasound, Mahon et al. (41) measured the length and a cross section of the distal femur in foetuses between 19 and 34 weeks of pregnancy. They found that in the 34th week of pregnancy, the $25(\mathrm{OH}) \mathrm{D}$ levels were inversely proportional to the femoral splaying index (distal cross-section / femur length). These results suggest that the maternal VD status already affects the bone morphology in the 19th week of pregnancy (41). 


\section{Hypocalcaemia in newborns}

In the view of what has been said above regarding the metabolism of VD and calcium during pregnancy, it is assumed that the concentration of calcium in a foetus and neonate depends on the maternal VD status (42). Studies evaluating how the supplementation of VD to mothers during pregnancy affects the homoeostasis of calcium in the newborn have shown higher serum calcium levels within the first week after birth, while the decline in the incidence of hypocalcaemia was more prevalent with $25(\mathrm{OH}) \mathrm{D}$ cord blood levels below $10 \mathrm{nmol} / \mathrm{l}$. Neonatal hypocalcaemia was only observed in the group receiving a placebo (43). The main clinical signs of hypocalcaemia in newborns are jitteriness and generalized convulsions, although asymptomatic hypocalcaemia has also been reported. Newborns may also be lethargic, eat poorly, vomit, and have abdominal distention. The degree of irritability does not appear to correlate with serum calcium values.

\section{Anthropometry in newborns}

The association between birth weight and maternal VD status or intake remains inconclusive. While some observational and interventional studies have found improvement in birth weight with maternal VD supplementation or improved VD status, several others did not confirm these findings (23). A recent longitudinal study (multi-ethnic cohort of 3,730 pregnant women) in The Netherlands, reported an increased risk for reduced foetal growth in women whose $25(\mathrm{OH}) \mathrm{D}$ concentration in early pregnancy was lower than 30 $\mathrm{nmol} / \mathrm{l}$ (44). This study has also found a link between a genotype for the VD receptor and the risk of reduced foetal growth. Morley et al. (45) showed a connection between a FokI genotype for the VD receptor and the newborn's size. FF or ff polymorphisms were associated with a lower birth weight if the mother had insufficient levels of VD, while neonates with ff polymorphism did not exhibit this association. Also, FokI polymorphism did not affect the size of the newborn if the maternal VD status was adequate (45). In addition, Robinson at al. reported lower maternal $25(\mathrm{OH}) \mathrm{D}_{3}$ concentrations in 56 women with early onset $\mathrm{PE}$ and small for gestational age (SGA) infants, vs. infants with normal foetal growth, suggesting the impact of VD on foetal growth through placental mechanisms (24). On the other hand, both studies - the longitudinal AVON, as well as the Southampton study - failed to show a link between the level of $25(\mathrm{OH}) \mathrm{D}$ and the birth weight and length of children $(46,47)$. A recently published meta-analysis of RCTs by Pérez-López et al. (22) also established the positive outcomes of VD supplementation in pregnancy regarding offspring birth weight and length. In summary, the current studies suggest that the risk of SGA and smaller birth size is possible when pregnant women are VD deficient or insufficient. However, the associations of maternal VD deficiency with early postnatal growth outcomes and infant adiposity are less clear, with inconsistent directionality and a smaller number of studies.

\section{Other impacts of maternal VD status on the offspring's health}

Consistent in vitro findings and observational clinical data have found an association between VD status in the cord blood and the lower incidence of respiratory tract infections in the first year of life. Cord blood $25(\mathrm{OH})$ D concentrations $<75 \mathrm{nmol} / \mathrm{l}$ have also been linked to infantile wheezing and eczema, possibly due to adverse consequences on the early immune development of the foetus. However, there is still not enough evidence to show whether VD supplementation increases or decreases the risk of allergies, and therefore this requires further exploration $(23,48)$. Re- 
garding neurocognitive development, while one study found no association between maternal VD status during pregnancy and neurocognitive function, a recent larger-sized study linked maternal serum $25(\mathrm{OH}) \mathrm{D}$ levels during pregnancy with language development in the offspring $(23,48)$.

\section{Conclusion}

The awareness of the importance of adequate VD intake during pregnancy, to achieve the optimal health of the mother and her offspring, is growing rapidly. In addition to the traditional role of $\mathrm{VD}$, which is associated with maintenance of calcium homoeostasis and bone health, new findings suggest that the mother's VD status plays an important role in ensuring the proper development of the placenta and foetus, and a proper immune response during pregnancy, as well as in achieving the optimal health of the offspring. The aetiology of the various maternal and foetal outcomes is complex and multifactorial, with many confounding factors. Most new insights on the importance of VD are based on observational studies, and require confirmation of the results by well-designed, randomized, placebo-controlled studies in which the studied group will receive additional VD during pregnancy (49). Determining the benefits of VD supplementation in pregnancy would require further evaluation through large, multicentre, double-blind randomized controlled clinical trials, with the focus on specific adverse pregnancy outcomes.

Authors' contributions: Conception and design: ASŠ and DPP; Acquisition, analysis and interpretation of data: ASŠ and DPP Drafting the article: ASŠ and DPP; Revising the article critically for intellectual content: ASS and DPP; Approved final version of the manuscript: ASŠ and DPP.

Conflict of interest: The authors declare that they have no conflict of interest.

\section{References}

1. Kovacs CS. Vitamin D, in pregnancy and lactation: maternal, fetal, and neonatal outcomes from human and animal studies. Am J Clin Nutr. 2008;88:520S-28S.

2. Karras SN, Anagnostis P, Bili E, Naughton D, Petroczi A, Papadopoulou F, et al. Maternal vitamin $\mathrm{D}$ status in pregnancy and offspring bone development: the unmet needs of vitamin D era. Osteoporos Int. 2014;25(3):795-805.

3. Holick MF. Resurrection of vitamin D deficiency and rickets. J Clin Invest. 2006;116(8):2062-72.

4. Holick MF. Vitamin D deficiency. N Engl J Med. 2007;357: 266-81.

5. Bodnar LM, Simhan HN, Powers RW, Frank MP, Cooperstein E, Roberts JM. High prevalence of vitamin D insufficiency in black and white pregnant women residing in the northern United States and their neonates. J Nutr. 2007;137:447-52.

6. Wagner CL, Taylor SN, Dawodu A, Johnson DD, Hollis BW. Vitamin D and its role during pregnancy in attaining optimal health of mother and fetus. Nutrients. 2012;4 (3):208-30.

7. Institute of Medicine. Dietary Reference Intakes for Calcium and Vitamin D. Washington, DC: The National Academies Press; 2011.

8. Holick MF, Binkley NC, Bischoff-Ferrari HA, Gordon CM, Hanley DA, Heaney RP, et al. Endocrine Society. Evaluation, treatment, and prevention of vitamin D deficiency: an Endocrine Society clinical practice guideline. J Clin Endocrinol Metab. 2011;96(7):1911-30.

9. Benedik E, Fidler Mis N. New recommendations for vitamin D intake (in Slovenian). Zdr Vestn. 2013;82:I145-I151.

10. Bikle D. Nonclassic actions of vitamin D. J Clin Endocrinol Metab. 2009;94(1):26-34.

11. Hollis BW, Wagner CL, Drezner MK, Binkley NC. Circulating vitamin D3 and 25-hydroxyvitamin D in humans: an important tool to define adequate nutritional vitamin D status. J Steroid Biochem Mol Biol. 2007;103:631-4.

12. Holick MF, Binkley NC, Bischoff-Ferrari HA, et al. Guidelines for preventing and treating vitamin $\mathrm{D}$ deficiency and insufficiency revisited. J Clin Endocrinol Metab. 2012;97:1153-58.

13. Hollis BW. Circulating 25-hydroxyvitamin D levels indicative of vitamin D sufficiency: impli- 
cations for establishing a new effective dietary intake recommendation for vitamin D. J Nutr. 2005; 135:317-22.

14. Hollis BW, Wagner CL. Vitamin D deficiency during pregnancy: an ongoing epidemic. Am J Clin Nutr. 2006;84:273

15. Hollis BW, Johnson D, Hulsey TC, Ebeling M, Wagner CL.Vitamin D supplementation during pregnancy: double-blind, randomized clinical trial of safety and effectiveness. J Bone Miner Res. 2011;26(10):2341-57.

16. Dawodu A, Wagner CL. Mother-child vitamin D deficiency: an international perspective. Arch Dis Child. 2007;92:737-40.

17. Weinert LS, Silveiro SP. Maternal-fetal impact of vitamin D deficiency: a critical review. Matern Child Health J. 2015;19(1):4-101.

18. Soltirovska Salamon A, Benedik E, Bratanič B, Velkavrh M, Rogelj I, Fidler Mis N, et al. Vitamin D Status and Its Determinants in Healthy Slovenian Pregnant Women. Ann Nutr Metab. 2015;67(2):96-103

19. Nguyen TP1, Yong HE, Chollangi T, Borg AJ, Brennecke SP, Murthi P. Placental vitamin D receptor expression is decreased in human idiopathic fetal growth restriction. J Mol Med (Berl). 2015;93(7):795-805.

20. Baker AM, Haeri S, Camargo CA Jr, Espinola JA, Stuebe AM. A nested case-control study of midgestation vitamin D deficiency and risk of severe preeclampsia. J Clin Endocrinol Metab. 2010;95(11):5105-9.

21. Bodnar LM, Simhan HN, Catov JM, Roberts JM, Platt RW, Diesel JC, Klebanoff MA. Maternal vitamin D status and the risk of mild and severe preeclampsia.Epidemiology. 2014 Mar;25(2):207-14.

22. Robinson CJ, Alanis MC, Wagner CL, Hollis BW, Johnson DD. Plasma 25-hydroxyvitamin D levels in early-onset severe preeclampsia. Am J Obstet Gynecol. 2010;203(4):366.e1-6.

23. Aghajafari F, Nagulesapillai T, Ronksley PE, Tough SC, O'Beirne M, Rabi DM. Association between maternal serum 25-hydroxyvitamin D level and pregnancy and neonatal outcomes: systematic review and meta-analysis of observational studies. BMJ. 2013;346:f1169.

24. Hewison M. Vitamin D and the immune system: new perspectives on an old theme. Endocrinol Metab Clin North Am. 2010;39:365-79.
25. Liu NQ, Kaplan AT, Lagishetty V, Ouyang YB, Ouyang Y, Simmons CF, et al. Vitamin D and the regulation of placental inflammation. J Immunol.2011;186(10):5968-74.

26. El Lithy A, Abdella RM, El-Faissal YM, Sayed AM, Samie RM. The relationship between low maternal serum vitamin D levels and glycemic control in gestational diabetes assessed by HbA1c levels: an observational cross-sectional study. BMC Pregnancy Childbirth. 2014;14:362.

27. Al-shoumer KAS, Al-essa TM. Is there a relationship between vitamin $\mathrm{D}$ with insulin resistance and diabetes mellitus? World J Diabetes. 2015;6(8):1057-64.

28. Tomedi LE, Simhan HN, Bodnar LM. Early pregnancy maternal vitamin $\mathrm{D}$ status and maternal hyperglycaemia. Diabetic Medicine: 2013;30(9):1033-39.

29. Lacroix M, Myriam MB. Lower vitamin D levels at first trimester are associated with higher risk of developing gestational diabetes mellitus. Acta Diabetol. 2014;51(4):609-16.

30. Thota C, Menon R, Fortunato SJ, Brou L, Lee J, Al-hendy A. 1 , 25-Dihydroxyvitamin D Deficiency Is Associated With Preterm Birth in African American and Caucasian Women. Reprod Sci. 2014;21(2):244-50.

31. Bodnar LM, Platt RW, Simhan HN. Early-Pregnancy Vitamin D Deficiency and Risk of Preterm Birth Subtypes. Obstet Gynecol. 2015;125(2):43947.

32. McDonnell SL, Baggerly KA, Baggerly CA, Aliano JL, French CB, Baggerly LL et al. Maternal 25(OH) D concentrations $\geq 40 \mathrm{ng} / \mathrm{mL}$ associated with $60 \%$ lower preterm birth risk among general obstetrical patients at an urban medical center. PLoS One. 2017; 12(7): e0180483.

33. Wagner CL, Baggerly C, McDonnell S, Baggerly KA, French CB, Baggerly L, Hamilton SA, Hollis BW. Post-hoc analysis of vitamin D status and reduced risk of preterm birth in two vitamin D pregnancy cohorts compared with South Carolina March of Dimes 2009-2011 rates. J Steroid Biochem Mol Biol. 2016;155 (Pt B): 245-51.

34. Pérez-López FR, Pasupuleti V, Mezones-Holguin E, Benites-Zapata VA, Thota P, Deshpande A, et al. Effect of vitamin D supplementation during pregnancy on maternal and neonatal outcomes: a systematic review and meta-analysis of randomized controlled trials. Fertil Steril. 2015;103(5):127888.e4. 
35. Hensel KJ, Randis TM, Gelber SE, Ratner AJ. Pregnancy-specific association of vitamin D deficiency and bacterial vaginosis. Am J Obstet Gynecol. 2011;204(1):41.e1-9.

36. Scholl TO, Chen X, Stein P. Maternal vitamin $\mathrm{D}$ status and delivery by cesarean. Nutrients. 2012;4(4):319-30.

37. Cross NA, Hillman LS, Allen SH, Krause GF, Vieira NE. Calcium homeostasis and bone metabolism during pregnancy, lactation, and postweaning: a longitudinal study. Am J Clin Nutr. 1995;61(3):514-23.

38. Wilson SG, Retallack RW, Kent JC, Worth GK, Gutteridge DH. Serum free 1,25-dihydroxyvitamin D and the free 1,25-dihydroxyvitamin $\mathrm{D}$ index during a longitudinal study of human pregnancy and lactation. Clin Endocrinol (Oxf). 1990;32:613-22.

39. Weiler H, Fitzpatrick-Wong S, Veitch R, Kovacs H, Schellenberg J, McCloy U, et al. Vitamin D deficiency and whole-body and femur bone mass relative to weight in healthy newborns. CMAJ. 2005;172(6):757-61.

40. Viljakainen HT, Saarnio E, Hytinantti T, Miettinen M, Surcel H, Mäkitie O, et al. Maternal vitamin $\mathrm{D}$ status determines bone variables in the newborn. J Clin Endocrinol Metab. 2010;95(4):1749-57.

41. Mahon P, Harvey N, Crozier S, Inskip H, Robinson S, Arden N, et al. SWS Study Group. Low maternal vitamin $\mathrm{D}$ status and fetal bone development: cohort study. J Bone Miner Res. 2010 Jan;25(1):14-9.

42. Harrington J, Perumal N, Al Mahmud A, Baqui A, Roth DE. Vitamin D and fetal-neonatal cal- cium homeostasis: findings from a randomized controlled trial of high-dose antenatal vitamin D supplementation. Pediatr Res. 2014;76(3):3029 .

43. Delvin EE, Salle BL, Glorieux FH, Adeleine P, David LS. Vitamin D supplementation during pregnancy: effect on neonatal calcium homeostasis. J Pediatr. 1986;109(2):328-34.

44. Leffelaar ER, Vrijkotte TG, van Eijsden M. Maternal early pregnancy vitamin $\mathrm{D}$ status in relation to fetal and neonatal growth: results of the multiethnic Amsterdam Born Children and their Development cohort. Br J Nutr. 2010;104:108-7.

45. Morley R, Carlin JB, Pasco JA, Wark JD, Ponsonby AL. Maternal 25-hydroxyvitamin D concentration and offspring birth size: effect modification by infant VDR genotype. Eur J Clin Nutr. 2009;63(6):802-4.

46. Sayers AA, Tobias JH. Estimated maternal ultraviolet $\mathrm{B}$ exposure levels in pregnancy influence skeletal development of the child. J Clin Endocrinol Metabol. 2009;94:765-71.

47. Javaid MK, Crozier SR, Harvey NC, Gale CR, Dennison EM, Boucher BJ, et al. Princess Anne Hospital Study Group. Maternal vitamin D status during pregnancy and childhood bone mass at age 9 years: a longitudinal study. Lancet. 2006;367(9504):36-43.

48. Triunfo S, Lanzone A. Potential impact of maternal vitamin D status on obstetric well-being. J Endocrinol Invest. 2016;39(1):37-44.

49. Heaney RP. Toward a physiological referent for the vitamin D requirement. J Endocrinol Invest. 2014;37(11):1127-30. 